\title{
STUDI RUANG KERJA PADA TEMPAT PELATIHAN PROSES BATIK STUDI KASUS: RUMAH BATIK PALBATU, JAKARTA
}

\author{
Augustina Ika Widyani' ${ }^{1}$, Maitri Widya Mutiara ${ }^{2}$, Muhammad Adi Pribadi ${ }^{3}$ \\ ${ }^{1}$ Program Studi Desain Interior, Universitas Tarumanagara Jakarta \\ Email: augustinaw@fsrd.untar.ac.id \\ ${ }^{2}$ Program Studi Desain Interior, Universitas Tarumanagara Jakarta \\ Email:maitrim@fsrd.untar.ac.id \\ ${ }^{3}$ Program Studi Ilmu Komunikasi, Universitas Tarumanagara Jakarta \\ Email:adip@fikom.untar.ac.id
}

Masuk : 01-04-2021, revisi: 21-04-2021, diterima untuk diterbitkan : 30-04-2021

\begin{abstract}
Rumah Batik Palbatu is the center of activities for Palbatu community in learning batik which is located in Jakarta. Until now, Rumah Batik Palbatu has been actively carrying out various programs to preserve and revive the image of batik, especially among young people. Rumah Batik Palbatu Jakarta serves every day from 09.00-16.00. With various activities taking place at Rumah Batik Palbatu Jakarta, the manager stated that the activities could not run optimally due to limited space and facilities. Therefore, this research on batik training workspace is intended to give advice for managers so that activities can run optimally. This study uses the Triangulation Method, that is used to review problems from various points of view, several sources of information and several forms of data, as well as several researchers to analyze in a broad perspective, especially those related to space or interior. The spatial arrangement at Rumah Batik Palbatu is based on the activity pattern. Grouping the types of activities is the main consideration to optimize the activities. Thus the activities do not overlap each other, especially in the implementation of training activities as the main activity of Rumah Batik Palbatu. The results of this study are in the form of an alternative workspace idea design for the manager of the Palbatu Batik House, as well as a cafe procurement plan that will be used for users.
\end{abstract}

Keywords: interior, workshop, batik, facilities.

\section{ABSTRAK}

Rumah Batik Palbatu adalah pusat aktivitas masyarakat Palbatu dalam belajar membatik yang berlokasi di Jakarta. Hingga saat ini Rumah Batik Palbatu telah aktif melakukan berbagai kegiatan untuk melestarikan dan mengangkat kembali citra batik terutama di kalangan anak muda. Rumah Batik Palbatu Jakarta beroperasi setiap hari dari jam 09.00-16.00. Dengan berbagai kegiatan yang berlangsung di Rumah Batik Palbatu Jakarta, pengelola menyatakan bahwa kegiatan belum dapat berjalan optimal karena keterbatasan ruang dan fasilitasnya. Oleh sebab itu penelitian ruang kerja pelatihan membatik ini ditujukan untuk memberikan masukan bagi pengelola agar kegiatan dapat berjalan dengan lebih optimal. Penelitian ini menggunakan Metode Triangulasi yang menerapkan beberapa metode digunakan untuk meninjau permasalahan dari berbagai sudut pandang, beberapa sumber informasi dan beberapa bentuk data, serta beberapa orang peneliti untuk memberikan analisis yang memiliki perspektif luas, terutama terkait studi ruang atau interior. Penataan ruang di Rumah Batik Palbatu disusun berdasarkan pola aktivitasnya. Pengelompokan jenis kegiatan merupakan pertimbangan utama agar setiap kegiatan dapat dilaksanakan dengan lebih optimal. Dengan demikian kegiatan tidak saling tumpang tindih, terutama dalam pelaksanaan kegiatan pelatihan sebagai kegiatan utama Rumah Batik Palbatu. Hasil dari penelitian ini adalah berupa alternatif rancangan ide Ruang Kerja bagi pengelola Rumah Batik Palbatu, serta usulan pengadaan kafe yang akan digunakan bagi para pengguna.

Kata Kunci: interior, pelatihan, batik, fasilitas.

\section{PENDAHULUAN}

\section{Latar Belakang}

Rumah Batik Palbatu Jakarta dikenal sebagai satu dari 8 (delapan) sentra batik yang ada di Indonesia (Nuraini, 2020), selain Kampung Laweyan Solo, Kampung Kauman Solo, Kampung Giriloyo Yogyakarta, Trusmi Cirebon, Bangkalan Madura, Girilayu Karanganyar, dan Putat Jaya Surabaya. Rumah Batik Palbatu ini dikenal dengan motif batiknya yang memiliki keunikan khas daerah Betawi. 
Gambar 1. Batik Motif Khas Betawi: Topeng Betawi, Kembang Api, dan Burung Gelatik

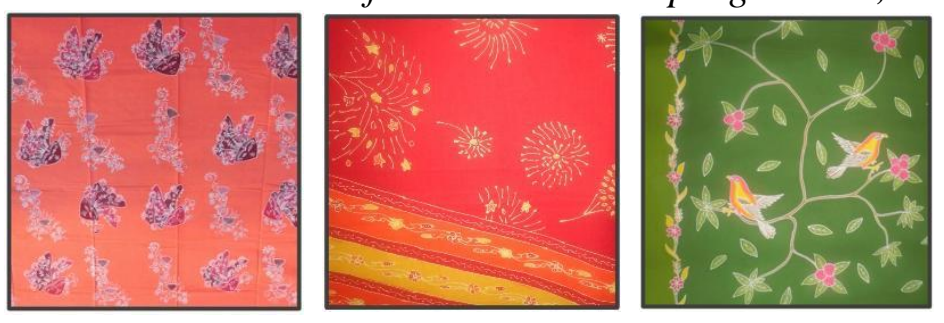

Sumber Gambar: Rumah Batik Palbatu, 2019

Kegiatan utama Rumah Batik Palbatu adalah pelatihan batik baik untuk perorangan maupun kelompok. Pelatihan batik untuk difabel, warga setempat dan anak jalanan tidak dipungut biaya. Program ini dikenal dengan nama Sedekah Batik (Haryanto, 2018). Awalnya berdirinya Rumah Batik Palbatu adalah untuk memberdayakan masyarakat setempat, dengan harapan masyarakat dapat meningkatkan kualitas hidup melalui kegiatan produktif membatik. Sebelumnya Jakarta memiliki banyak industri batik dengan teknik celup seperti yang berada di daerah Karet, Kebon Kelapa dan Gambir. Namun kemudian industri tersebut ditutup karena melanggar kebijakan AMDAL (Analisis Mengenai Dampak Lingkungan). Sementara itu teknik membatik yang dikembangkan di Rumah Batik Palbatu adalah teknik colet yang ramah lingkungan.

\section{Rumusan Masalah}

Dengan tingginya intensitas kegiatan pelatihan membatik di Rumah Batik Palbatu, serta jumlah peserta per-kelompok yang mengikuti kegiatan, pengelola kesulitan untuk mengatur ruang yang tersedia sebagai area pelatihan. Saat ini Rumah Batik Palbatu yang berlokasi di Menteng Dalam, Kecamatan Tebet, Jakarta Selatan, terdiri dari ruang workshop, ruang administrasi, ruang rapat dan pantry, dan kamar mandi, sebagaimana terlihat pada Gambar 2 berikut ini.

Gambar 2.

\section{Denah Eksisting Rumah Batik Palbatu}

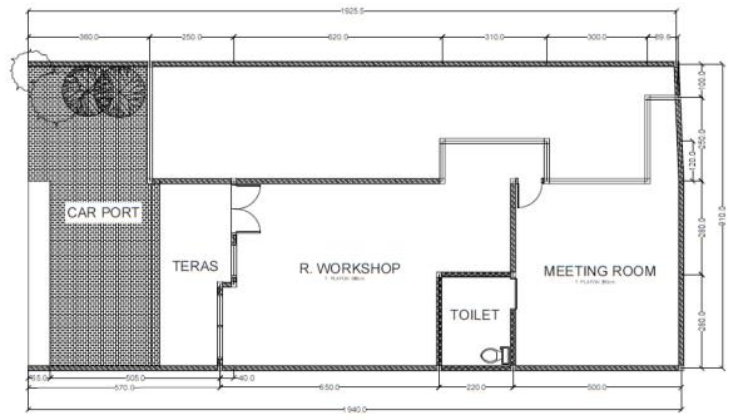

\section{DENAH RUMAH BATIK}

Sumber Gambar: Widyani, Mutiara, \& Pribadi, 2019

Dari data denah eksisting tersebut di atas terlihat bahwa area yang digunakan untuk pelatihan adalah 6,5x5,6 m2. Kecuali bila kain yang dibatik ukurannya cukup panjang, maka ruang Workshop hanya dapat menampung 1 (satu) bentangan kain saja seperti terlihat pada Gambar 3 . Selebihnya tahap pelorodan dan pengecekan hasil akhir menggunakan teras sebagaimana ditunjukkan pada Gambar 4 (Widyani, Mutiara, \& Pribadi, 2019). 
Gambar 3.

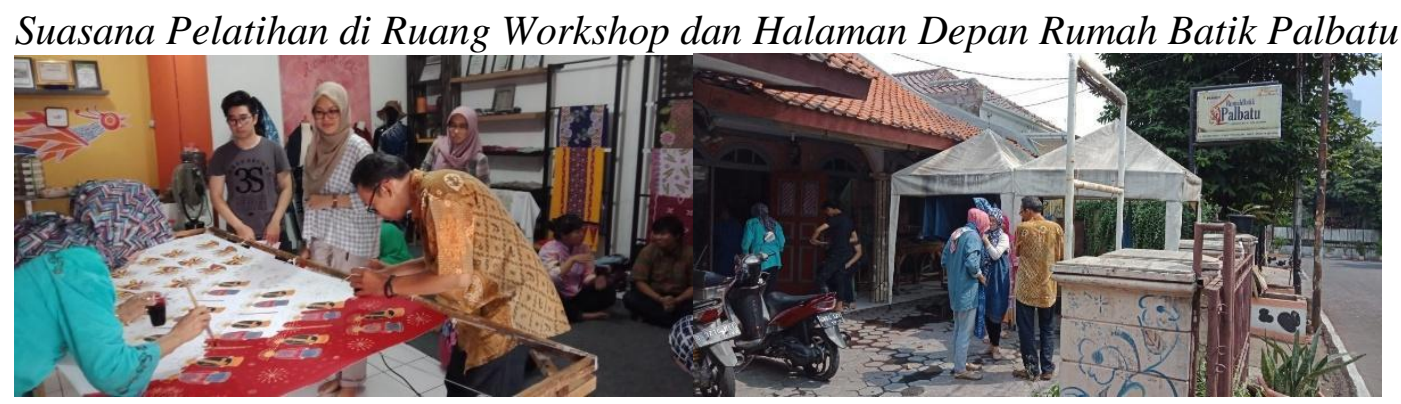

Sumber Gambar: Widyani, Mutiara, \& Pribadi, 2019

Besaran ruang Workshop tersebut dapat menampung 2 (dua) grup peserta dengan masing-masing grup terdiri dari 5 (lima) orang peserta. Artinya bila jumlah peserta pelatihan lebih dari 10 (sepuluh) orang, maka ruangan tidak dapat menampung seluruh peserta. Sehingga diperlukan pengaturan ruang dan fasilitas yang lebih baik untuk mengoptimalkan ruang yang tersedia.

\section{METODE PENELITIAN}

Penelitian ini merupakan penelitian kualitatif, dengan menganalisis data fisik maupun non fisik untuk mendapatkan mengetahui tuntutan ruang yang mendukung aktivitas pelatihan dan penjualan (display) batik. Focus Discussion Group (FDG) merupakan salah satu bentuk diskusi ilmiah dari beberapa pihak terkait yang memiliki latar belakang keilmuan terkait studi ruang untuk ruang pelatihan dan penjualan, untuk mendapatkan berbagai masukan dan koreksi terhadap proses analisis yang berlangsung.

Penelitian ini dapat dikategorikan sebagai penelitian dengan metode triangulasi karena keterlibatan beberapa sumber informasi, beberapa bentuk data, beberapa pihak yang melakukan analisis dan merumuskan kesimpulan, serta beberapa teori yang berbeda dalam menganalisis data. Data yang dikumpulkan dengan berbagai teknik akan mempengaruhi proses analisis maupun hasil analisisnya. Untuk pengumpulan data, teknik yang digunakan adalah studi literatur terhadap teori dan studi kasus mengenai teori spasial, studi lapangan berupa observasi dan wawancara ke Rumah Batik Palbatu terutama ketika sedang berlangsungnya program kegiatan mereka, serta dokumentasi berupa pencatatan dan pengambilan foto di lokasi untuk dukungan proses analisis.

Teknik analisis data yang digunakan dalam penelitian pengembangan ini adalah menggunakan teknik analisis deskriptif kualitatif, yaitu melalui pemaparan data dan simpulan data, sehingga data statistik yang digunakan adalah sebagai pelengkap untuk menguji hipotesis dalam penelitian.

\section{HASIL DAN PEMBAHASAN}

\section{Analisis Spasial Desain Interior}

Sebagaimana dikemukakan oleh Mary Lou Bakker (Bakker, 2012) bahwa ada 5 (lima) kategori yang merupakan garis besar komponen perencanaan ruang. Penelitian ini difokuskan pada kategori klien dan elemen ruang. Kategori klien akan mencakup jenis bisnis, kebutuhan ruang, suasana yang diharapkan, anggaran dan jadwal pelaksanaan. Sedangkan elemen ruang akan membahas permasalahan furniture, ukuran ruang, sirkulasi, konstruksi.

Klien yang dimaksud pada pembahasan ini adalah pengguna ruang yang terdiri dari: (a) Pemilik dan pengelola; (b) Peserta workshop; (c) Pengunjung dan pembeli. Pemilik dan pengelola adalah warga setempat yang kemudian mengembangkan industri batik sistem colet yang tidak menghasilkan limbah (zero waste). Mereka ini adalah pengrajin batik yang memiliki kepedulian 
terhadap kesejahteraan masyarakat setempat, sehingga Rumah Batik Palbatu terbuka untuk masyarakat setempat berlatih dengan gratis. Beberapa pengelola merupakan pengrajin batik yang sudah bersertifikasi, sehingga dapat membantu pengrajin lain untuk mendapatkan sertifikasi sebagai pengrajin batik.

Peserta workshop dapat dikategorikan menjadi peserta umum dan peserta difabel. Peserta umum biasanya mendaftar perorangan atau kelompok untuk mengikuti workshop dengan sistem paket sebagaimana ditawarkan oleh Rumah Batik Palbatu. Peserta perorangan melakukan pelatihan di Rumah Batik Palbatu, sementara peserta kelompok dengan jumlah yang besar biasanya melakukan pelatihan di tempat mereka. Sementara peserta difabel adalah peserta program Sedekah Batik yang tidak dipungut biaya.

Jenis bisnis yang ditemukan pada Rumah Batik Palbatu adalah kegiatan pelatihan dan penjualan batik. Oleh karena itu kemudian sebagaimana disebutkan sebelumnya bahwa kelompok aktivitas yang terjadi dapat dibedakan menjadi 3 (tiga) yaitu: (a) kelompok aktivitas pengelola: diskusi dengan pengunjung, perencanaan kegiatan, dll; (b) kelompok aktivitas pelatihan: membuat pola, nyanting, pewarnaan, pelorotan, penjemuran; (c) kelompok aktivitas promosi: penjualan, display. Dari pengelompokan aktivitas tersebut di atas maka ruang yang tersedia dapat dianalisa ke dalam zona-zona kelompok aktivitas berikut:

Gambar 5.

\section{Analisis Zonasi Rumah Batik Palbatu}
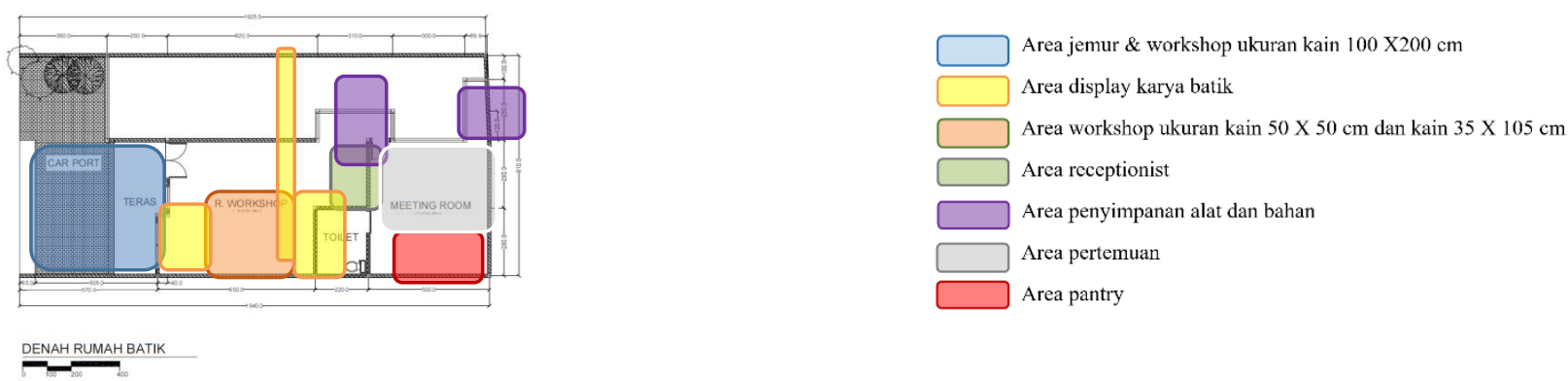

Sumber Gambar: Widyani, Mutiara, \& Pribadi, 2019

Saat ini pengaturan ruang sudah sesuai dengan alur kegiatan yang terjadi di Rumah Batik Palbatu, hanya saja pada pelaksanaannya kurang tertib sehingga ruangan tampak tidak rapi. Oleh karena itu fungsi display dan fungsi penyimpanan disarankan agar diatur kembali agar memiliki tempattempat pajang dan penyimpanan yang sesuai dengan kebutuhan.

Suasana yang diharapkan adalah suasana yang santai dengan semangat kekeluargaan sesuai dengan yang tujuan Rumah Batik Palbatu, ingin melestarikan batik dengan menjadikannya sebagai bagian dari gaya hidup masyarakat pada umumnya. Menjadikan batik sebagai bagian dari gaya hidup bukan saja dalam bentuk pakaian yang dikenakan sehari-hari, tapi termasuk kegiatan membuat batik agar lebih dikenal dan dicintai oleh masyarakat.

Penelitian ini tidak termasuk dalam perencanaan biaya dan jadwal pelaksanaan, sehingga akan menghasilkan usulan-usulan desain yang dapat dipertimbangkan oleh pemilik untuk direalisasikan. Penelitian ini akan meninjau kesesuaian beberapa komponen spasial terhadap kelancaran aktivitas yang terjadi. Saat ini kelompok aktivitas yang terjadi di Rumah Batik Palbatu dapat dibedakan menjadi: (a) kelompok aktivitas pengelola: diskusi dengan pengunjung, perencanaan kegiatan, dll; (b) kelompok aktivitas pelatihan: membuat pola, nyanting, pewarnaan, pelorotan, penjemuran; (c) kelompok aktivitas promosi: penjualan, display. 
Menurut Rengel (2012), desain proses terdiri dari beberapa tahapan. Perencanaan spasial sendiri diidentifikasikan dalam proses desain 1 dan proses desain 2. Proses desain 1 merupakan program diagramatik yang menunjukkan kebutuhan terhadap jenis ruangan sebagai bentuk wadah aktivitas. Proses desain 2 sudah memasuki fisik ruangan yang terbentuk dengan ukuran-ukuran tertentu yang membatasi gerak aktivitas yang terjadi. Tahapan ini dapat disebut sebagai desain awal (preliminary design). Dari kelompok aktivitas yang diamati selama proses observasi, dapat ditentukan block plan sesuai dengan alur aktivitas masing-masing kelompok kegiatan.

Block plan yang dihasilkan merupakan bentuk simulasi ruang dan area yang direncanakan. Tahapan selanjutnya adalah mengembangkan block plan ini menjadi loose plan, sebagai bentuk yang lebih rinci dengan perencanaan sirkulasi, dinding, bukaan dan beberapa furniturnya.

Pengembangan selanjutnya adalah mendapatkan beberapa alternatif penataan ruang yang masingmasing memiliki kekurangan dan kelebihannya masing-masing. Dari pemilihan satu penataan ruang dengan kelebihan terbanyak dan kekurangan paling sedikit, didapatkan alternatif terbaik untuk sebuah perencanaan desain interior.

Dari pembagian area berdasarkan kelompok aktivitas tersebut di atas, didapatkan 2 (dua) alternative block plan yang kemudian dianalisis terutama dari aspek sirkulasinya. Sirkulasi sangat menentukan keefektifan suatu aktivitas berlangsung, dengan tetap memperhatikan tuntutan lain seperti privasi maupun kedekatan antar area.

Gambar 6.

Pembagian Area Berdasarkan Kelompok Kegiatan

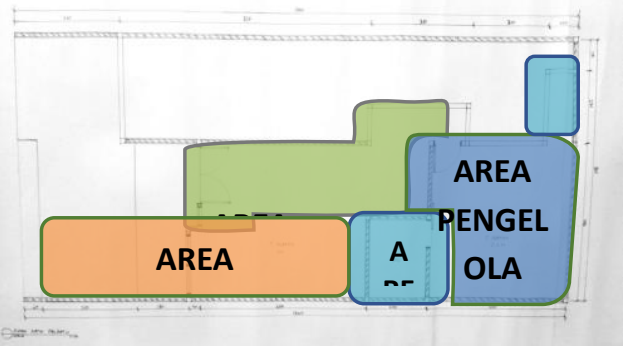

Sumber Gambar: Widyani, Mutiara, \& Pribadi, 2019

Pada block plan alternatif pertama didapatkan perluasan area jendela ke arah teras untuk mendapatkan area window display tempat meletakkan mannequin dengan busana yang terbuat dari kain batik hasil produksi Rumah Batik Palbatu. Letak reception area tidak menghalangi sirkulasi.

Alternatif kedua memberikan sirkulasi yang lebih baik karena bersifat langsung. Sesuai dengan jenis kegiatan utama yang berlangsung dalam hal ini adalah pelatihan, maka di Rumah Batik Palbatu tidak dituntut tingkat privasi yang tinggi, berbeda dengan tuntutan untuk rumah tinggal. 
Gambar 7.

Alternatif 1 dan 2 Block Plan
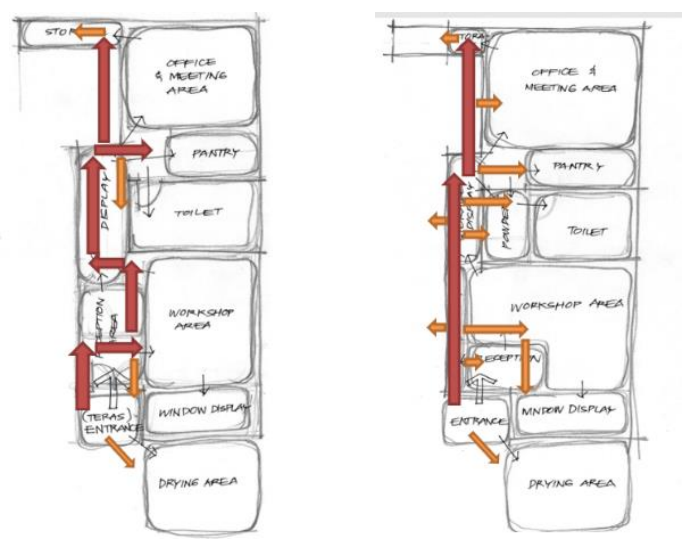

Sumber Gambar: Widyani, Mutiara, \& Pribadi, 2019

\section{Analisis Proksemik dan Ergonomi}

Proksemik adalah sebuah studi terhadap hubungan antara manusia dengan budaya tertentu dan penggunaannya serta persepsinya terhadap ruang (Hall , 1990). Desainer interior mempelajari bagaimana manusia berinteraksi untuk pemahaman yang lebih baik terhadap masyarakat, aspek fisik dan psikologis dari ruang. Kemudian dengan berdasarkan pada pengetahuan ini desainer merencanakan ruang untuk pengguna sehingga dapat bergerak dengan lebih nyaman baik secara fisik maupun psikologis.

Teori ini menjadi pertimbangan dalam penataan ruang, bagaimana antar pengguna ruang di Rumah Batik Palbatu saling berinteraksi satu sama lain. Sirkulasi dan jarak antar furniture mempengaruhi ruang yang terbentuk untuk penggunanya saling berinteraksi. Oleh karena itu pada sebuah fasilitas pelatihan, permasalahan ini sangat penting untuk mencapai kualitas interaksi (dalam hal ini pelatihan dan sosialisasi) yang sangkil dan mangkus.

Sifat pelatihan yang dilaksanakan di Rumah Batik Palbatu menuntut interaksi yang aktif antara instruktur dan peserta latihan. Untuk itu jarak komunikasi yang dituntut termasuk dalam jarak personal sehingga memungkinkan adanya interaksi dua arah. Terlebih untuk peserta pelatihan difabel yang mengandalkan gerakan bibir instruktur untuk memahami arahan dalam setiap tahapan pelatihan. Oleh karena itu jumlah peserta pelatihan yang dapat ditampung di area pelatihan Rumah Batik Palbatu harus dibatasi tidak lebih dari 15 (lima belas) orang. Ketika jumlah peserta pelatihan melebihi kapasitas area pelatihan yang tersedia, maka pelatihan tidak akan berlangsung efektif. Solusinya adalah melakukan pelatihan di tempat lain dengan koordinasi dengan para peserta.

Peserta pelatihan batik melakukan kegiatannya dengan duduk di meja rapat untuk membuat pola batik sebagaimana layaknya orang membuat gambar, kemudian melanjutkan dengan mencanting yang dilakukan di ruang workshop dengan menggunakan peralatan mencanting yaitu tungku dan wadah lilin. 
Gambar 8.

Posisi Duduk Mencanting

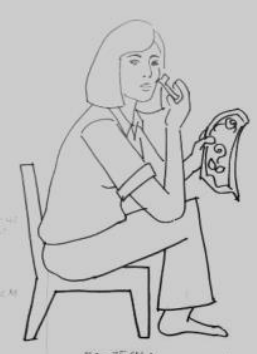

Sumber Gambar: Widyani, Mutiara, \& Pribadi, 2019

Kegiatan mencanting ini dilakukan dengan duduk di atas bangku rendah untuk menyesuaikan dengan posisi tungku dan wadah lilin batik. Posisi kaki peserta dapat ditekuk ke depan atau ditekuk ke samping. Posisi tekuk depan tidak menghabiskan tempat (ringkas), sementara posisi tekuk samping lebih menghabiskan tempat. Namun karena waktu pengerjaan yang tidak singkat, maka peserta harus dapat merubah posisi dari tekuk depan menjadi tekuk samping untuk menghilangkan penat.

Gambar 9.

Analisis Jumlah Peserta dalam Grup Mengelilingi Tungku, Posisi Kaki Tekuk Depan (kiri) dan Tekuk Samping (kanan)
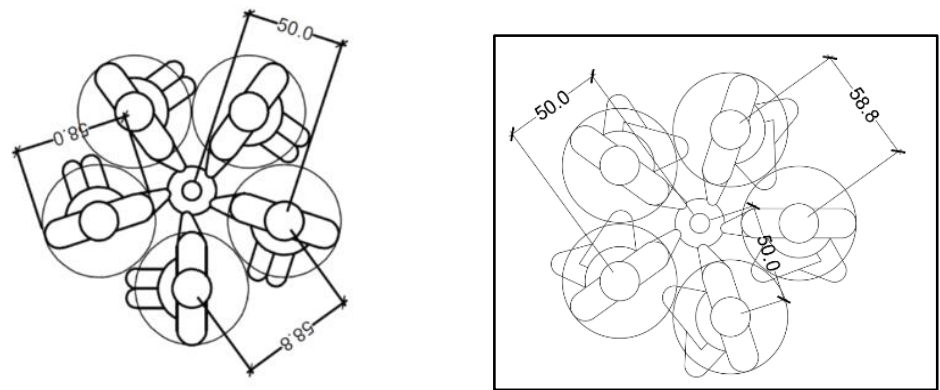

Sumber Gambar: Widyani, Mutiara, \& Pribadi, 2019

Analisis menunjukkan bahwa satu tungku lilin dapat efektif digunakan bersamaan oleh 5 (lima) orang peserta pelatihan. Berdasarkan teori proksemik, jarak personal berkisar antara 18" atau 45 cm sampai 4' atau 101,6 cm. Pada analisis diambil jarak $58 \mathrm{~cm}$, sehingga memberikan jarak memungkinkan masing-masing peserta leluasa bergerak tanpa mengganggu area personal peserta lain. Apabila satu tunggu digunakan oleh 6 (enam) orang peserta latihan, maka lingkaran grup harus diperbesar sehingga masing-masing peserta akan kesulitan dalam mengambil lilin dari atas tungku. Oleh karena itu jumlah grup yang disarankan maksimal adalah 5 (lima) orang. 
Gambar 10.

Layout Workshop dengan 3 (Tiga) Grup Pembatik, Duduk di Kursi Rendah dengan Kaki Tekuk Depan (kiri) dan Kaki Tekuk Samping (kanan)
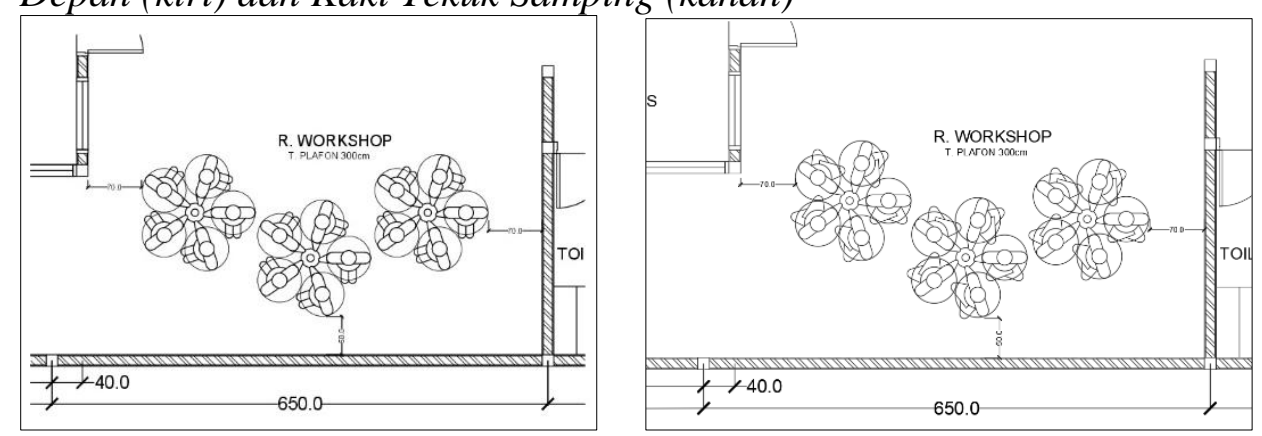

Sumber Gambar: Widyani, Mutiara, \& Pribadi, 2019

\section{Pengembangan Desain Interior}

Penelitian yang pernah dilakukan sebelumnya oleh peneliti lain terkait dengan perencanaan tempat pelatihan batik menekankan pada desain tematik maupun desain furniture. Penelitian pada pusat pelatihan batik yang dilakukan oleh Hutomo dan Setiawan (2014) menawarkan konsep The Modern Art of Batik untuk menarik minat masyarakat dalam rangka melestarikan batik. Melalui pendekatan yang modern diharapkan batik lebih diterima oleh masyarakat masa kini.

Penelitian yang terkait dengan galeri batik dilakukan oleh Irawan dan Indraprasti (2017). Rumah Batik Jawa Timur ditujukan untuk mengembangkan dan melestarikan batik Jawa Timur. Penelitian ini kemudian mengangkat berbagai ukiran dari peninggalan Majapahit, Madura, dan transformasi motif batik dan eksplorasi material batu bata sebagai ciri khas candi-candi Jawa Timur.

Selanjutnya juga ditemukan adanya penelitian terhadap display kain batik yang dilakukan oleh Fauzi (2014). Penelitian ini mengkaji penerapan karakter tertentu pada display vitrin untuk koleksi batik klasik.

Ketiga penelitian tersebut di atas menekankan pada konsep tematik ruang pelatihan maupun ruang pamer batik. Berbeda dengan penelitian spasial yang dilakukan pada Rumah Batik Palbatu ini, penekanannya adalah pada efektifitas penggunaan ruang dikarenakan keterbatasan ruang yang dimiliki. Dengan pengembangan berdasarkan block plan alternatif pertama maka didapatkan alur sirkulasi berikut:

Gambar 11.

Pola Tata Ruang dan Pola Sirkulasi Radial dari Pengembangan Block Plan Pertama

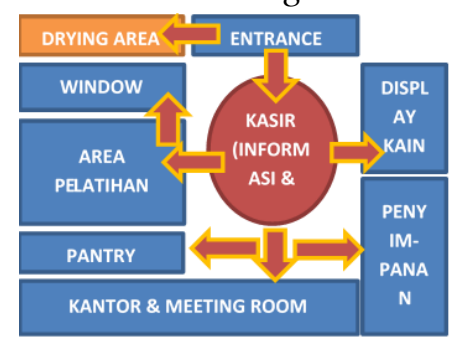

Sumber Gambar: Widyani, Mutiara, \& Pribadi, 2019 
Selanjutnya berdasarkan pola sirkulasi tersebut di atas, dikembangkan menjadi layout Rumah Batik Palbatu dengan beberapa perubahan pada pencapaian beberapa ruang sebagai berikut:

Dari tata ruang tersebut maka ruang dapat dioptimalkan dengan merubah pencapaian ke dalam ruang rapat, sehingga mendapatkan area penyimpanan yang lebih luas. Demikian juga toilet dirubah pintunya sehingga pencapaian tidak melalui ruang rapat melainkan dari area penyimpanan sehingga lebih mudah dicapai dari ruang workshop. Penataan di dalam toilet juga diperbaiki sehingga lebih efektif untuk aktivitas di dalamnya. Selain itu area di depan toilet memungkinkan untuk dijadikan area bilas tangan dengan menempatkan wastafel.

Pada alternatif pertama lay-out Rumah Batik Palbatu, memungkinkan untuk penempatan area office untuk keperluan administrasi pelatihan batik. Sementara untuk alternatif kedua lebih dioptimalkan untuk penyimpanan bahan dan material untuk keperluan pelatihan batik.

Gambar 12.

Alternatif Layout 1 dengan Area Office (kiri) dan 2 untuk Optimalisasi Area Penyimpanan (kanan)
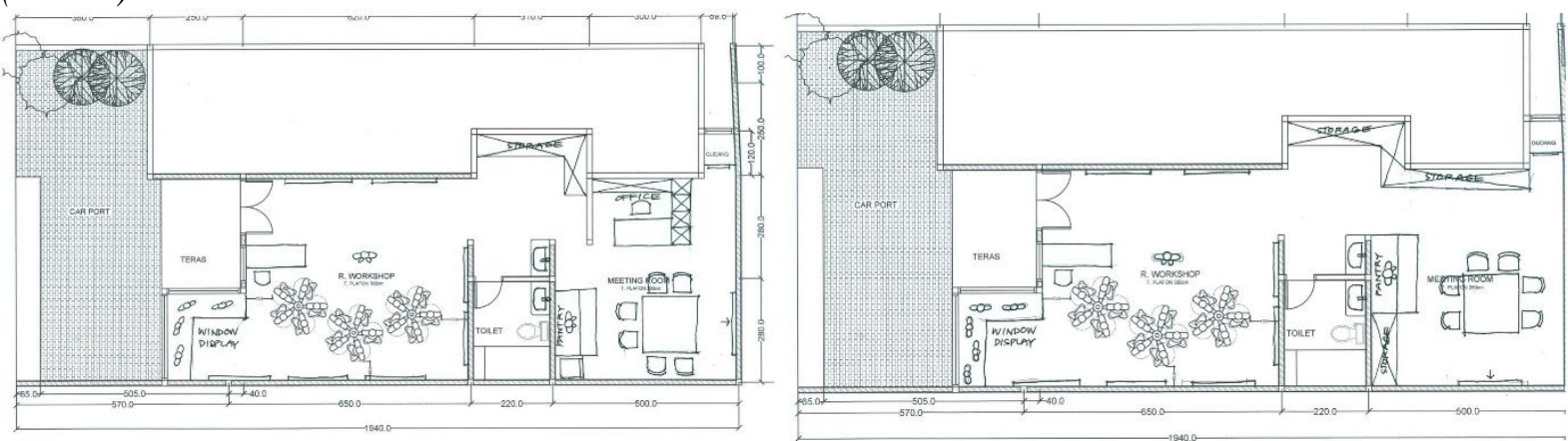

Sumber Gambar: Widyani, Mutiara, \& Pribadi, 2019

\section{KESIMPULAN DAN SARAN}

Dengan kondisi yang ada saat ini, tanpa merubah struktur bangunan yang ada, perbaikan masih dapat dilakukan dengan tujuan untuk mengoptimalkan fungsi dan ruang. Dengan analisis alur aktivitas dan kebutuhan ruang serta fasilitas pada Rumah Batik Palbatu, maka ruang yang diperbaiki adalah bagian depan ditambahkan window display untuk memperkuat informasi fungsi Rumah Batik Palbatu. Juga bagian belakang beberapa dinding perlu dibongkar untuk penyesuaian letak pintu ke ruangan tertentu.

Gudang bagian belakang dipangkas dengan menggeser letak dinding sehingga tidak jauh dari ruang workshop. Tujuannya adalah untuk membantu sirkulasi udara area rapat.

Setiap makalah diakhiri dengan kesimpulan, yang merangkum hasil dari makalah yang ditulis, serta saran sebagai rekomendasi yang dihasilkan dari penelitian.

Ucapan Terima Kasih (Acknowledgement)

Terima kasih kepada Bapak Budi Dwi Haryanto selaku pemilik Rumah Batik Palbatu yang telah memberikan informasi yang diperlukan untuk penelitian ini.

\section{REFERENSI}

Bakker, M. L. (2012). Space planning for commercial office interiors. Fairchild Books.

Fauzi, M. (2014). Karakteristik desain display untuk koleksi kain batik klasik dengan pendekatan analogi motif batik yang berdasarkan filosofinya. Inosains 9(2), 82-91.

Hall , E. T. (1990). The hidden dimension. Anchor Book. 
Haryanto, B. D. (2018, July 14). Rumah Batik Palbatu. (A. I. Widyani, Interviewer)

Hutomo, H., \& Setiawan, A. P. (2014). Perancangan Interior Pusat Pelatihan Batik di Surabaya. Jurnal Intra, 2(1).11-16.

Irawan, R. A., \& Indraprasti, A. (2017). Desain Interior Galeri Rumah Batik dengan Konsep Jawa Timur Kontemporer sebagai Sarana Workshop dan Edukasi. Jurnal Sains dan Seni ITS, 6(1) $2337-3520$

Nuraini, D. (2020, Oktober).Sejarah 8 Sentra Batik Indonesia. kabar24bisnis.com. Diambil dari https://kabar24.bisnis.com/read/20201002/79/1299664/sejarah-8-sentra-batik-indonesia

Rengel, R. J. (2012). The Interior Plan. New York: Fairchild Books.

Widyani, A. I., Mutiara, M. W., \& Pribadi, M. A. (2019). Studi Ruang Kerja pada Interior Rumah Batik Palbatu, Jakarta. Universitas Tarumanagara. 